\section{GENETICS AND THE ADVANCEMENT OF SCIENCE}

T

HAT zoologists and botanists on September 6 devoted a whole day's joint session at the British Association meeting at Oxford to discuss genetics in relation to other biological sciences is perhaps evidence enough for its importance and central position. The subjects covered by tho speakers, which included taxonomy and evolution, biometry and animal and plant breeding, medicine, physiology and microbiology, confirm this view. If this were not proof enough, the different methods of exposition adopted by the speakers-the historical, the broad generalization, the concrete examples illustrating one or two points, the read paper and the extempore-were in themselves a living and immediate demonstration of the great influence genetics has on human behaviour-that subtle character which is generally believed to be most tractable. This unconscious genetic experiment had its control group, for three of the speakers, all of them different in their methods, come from the same environment-the school founded by Bateson. If identical twins, trained in different schools, had been included among the speakers the experimental design would have been well-nigh perfect.

In discussing taxonomy, Prof. J. Heslop-Harrison said that almost every aspect of genetical research is relevant to taxonomy, but it would not cause a revolution in the system. Its contribution was to be found in the concept of a species as a biological unit, and that species differed generally in complex genic or structural chromosomal differences which had accumulated gradually over a long period. Genetics had revealed the nature of interspecific barriers, and a study of breeding systems as well as chromosomal analysis was essential for the proper assessment of a group : evidence for this was seen in the difficult taxonomic genera which had since been found to have an unorthodox breeding system such as apomixis. Because the full effect of genetical research had not yet been felt in taxonomy, a plea was made for reciprocal exchange of ideas and results from the two disciplines. Perhaps the speaker was unaware that geneticists are often greatly impressed with classification, because its groupings are usually confirmed by genetical studies. It would be too much to hope that genetics could give to the whole of classification the meaning and unity which atomic physics has given to the far simpler classification of the atomic table, but in some families a comparable correspondence between taxonomic differences and genetic structure can be found.

Prof. K. Mather, in his historical account of the internecine war within genetics between the GaltonPearson group of biometricians and the Bateson school of Mendelians, traced its origin to the entirely different experimental approach adopted by the two sides to the problem of heredity. Mendel studied single sharply defined characters in carefully chosen material, the pure breeding pea, and he ignored all other variation. The confirmation of Mendel's laws by Bateson in many other plants and animals showed its wide application. Galton and Pearson, on the other hand, attempted to take into account the whole of the variation by measuring individuals, and dividing the variation into heritable and nonheritable from the correlations of these measurements for parent and offspring. The type of con- tinuous variation found by Galton did not agree with the discontinuous variation found by Mendel. The synthesis of these was made by Sir Ronald Fisher in 1918 when he showed that a continuously variable character such as height in man could be explained on Mendelian laws by merely postulating a number of genes each with a small effect. This synthesis has been developed and is now being applied to practical breeding. But Prof. Mather pointed out that present biometrical methods such as the analysis of variance were unable to cope with the great complexities of gene interactions which occur with such polygenic systems.

Darwin was handicapped when formulating his theory of evolution by not having a basis for heredity, for he was unaware of Mendel's work. 'This importance of genetics for the interpretation of evolution was illustrated by Dr. E. B. Ford, who described his recent researches in the laboratory and field with butterflies. Much of Dr. Ford's earlier work had shown that the expression of a heterozygote could be altered by selection, as originally postulated by Fisher. In other words, the dominance properties of a gene could be changed. A colour pattern which in the wild was controlled by a gene with incomplete dominance - the heterozygote being intermediate between the two dominants - could be easily changed to full dominance by selection in the laboratory. That dominance was not present in the wild indicated that the heterozygotic intermediate phenotype had some selective advantage over the two homozygotes. Polymorphism for wing spotting in wild population in south-east England and the Scilly Isles had been mapped in relation to natural barriers. Small changes in vegetation in areas across an island were enough to separate populations having either a bimodal or a unimodal distribution of spots.

Turning to the practical application of genetics : Dr. A. Robertson pointed out how the early attempts in animal breeding to combine high milk yield and high fat content had failed to give the expected results on Mendelian theory, because the synthesis of biometry and mendelism had not then been made. The large number of genes concerned in these two characters, even without the complication of linkage, would require very large progenies to recover the desired combination. But the biometrical back. ground had since been applied to practical problems with great success, particularly in the United States. A principle had emerged that with a character of high selective value there would be little genetic variation left on which to make further selection, but with a character of low selective value there would be a store of genetic variation. The application of genetic principles depended upon the type of breeding system adopted by the whole society of stock raisers. The selling of bulls from a few herdsbulls which conform to the fashionable but false standard of shape-means that all the herds of a breed are permeated with the genes from the few bull-selling herds. The use of such bulls within the existing breeding system was the cause for the failure of artificial insemination to increase milk yields. To get the full value of artificial insemination the criteria for selecting bulls must be changed.

The plant and animal breeders' problems are fundamentally similar, but differ in detail such as the number of individuals that can be raised. The large and expensive animal is a severe limitation on numbers which would never trouble a wheat breeder. 
Prof. S. C. Harland described how plant selectors and hybridists without any genetical knowledge had obtained great success. But this was due to the accommodating nature of their material, and the use of genetical principles would have speeded the results. The concept of 'gene erosion' was a problem which all breeders had to face. Rigorous selection for one character was usually accompanied by a loss of 'fitness' genes. For example, the selection of large flowers in sweet peas had produced sterility under certain conditions. Such unbalanced types would not survive in the wild; but the unbalance was to a certain extent counteracted by the artificial environment of agriculture. Thus the main problem is one of genotype and environment, the study of which requires both genetics and physiology. Another important factor was mutability, for the problem of releasing variability in some material is a real handicap to the breeder. To-day, plant improvement rests largely on complex characters such as disease resistance, and hence a full knowledge of the genetics and biochemistry of physiological races is necessary.

The problems of human geneties have to be tackled differently from those in animals and plants. Prof. L. R. Penrose showed how many different morphological and physiological peculiarities are known now to be due to single genes. Some of these effects can be mitigated by treatment, others cannot. There was a fallacy in the argument advanced by some geneticists that under the cover of improved hygiene and nutrition the population is said to be deteriorating genetically. The example of the relationship between sickle-cell anæmia and resistance to malaria was evidence for this fallacy, for it showed that a gene need not necessarily be wholly good or bad. The gene for sickle-cell anæmia in a heterozygote confers complete resistance to malaria, a property which is of obvious advantage in tropical countries. In this case the hygienic control of malaria actually reduces the incidence of the sicklecell gene. The full physiological effects of genes and the future requirements of the human race are not: known, and since variety is generally advantageous it was an unsound policy to try and get rid of genes by sterilization.

The physiological effects of genes was discussed by Dr. D. Lewis, who stated that the gene, although its conception had changed from the billiard ball to \& piece of chromosome of varying complexity and length, was still a working physiological unit. The effects of the gene controlling sexual incompatibility in plants was known in sufficient detail to enable us to draw a close parallel between the type of genetic control and the physiological mechanism. This relationship between genetics and physiology had a predictive value which could be applied to quite different systems; for example, to the relationship between a host plant and its fungal parasite. The cytoplasm-that other hereditary factor, less rigorous and usually subservient to the gene but a factor which plays the major part in differentiation, ageing and perhaps short-term adaptation-was now beginning not to obey rules but at least to show remarkably similar properties in organisms as diverse as the tomato, fruit fly, Paramecium and yeast. Since the gene was the prime cause of all physiological effect, and the cytoplasm was the means of transmitting that effect, a genetic study from the gene outwards and a physiological study inwards provided a fruitful meeting ground for collaboration.
The application of genetics to micro-organisms, particularly those which have no normal sexual cycle, was described by Dr. J. A. Roper (in a joint contribution with Dr. G. Pontecorvo). On the classical genetic theory the reassortment of genes required sexual reproduction, but in several asexual micro-organisms a 'para sexual' phenomenon occurred which made genetic analysis possible. In bacteria, transformation by a pure nucleic acid occurred; in filamentous fungi, exchange of whole chromosomes or even somatic crossing-over occurred. Micro-organisms were particularly suitable for physiological genetics where the specificity of each gene determining a single biochemical reaction had been found in great numbers.

The importance of micro-organisms was emphasized by Prof. C. D. Darlington in his summing-up. In micro-organisms development was telescoped in such a way that the gene was closer to the character, until in the virus the gene and the character were one. The almost unnoticed demonstration in 1924 of the precise segregation of characters in the four spores of a moss transferred Mendel's laws from a statistical to a direct observational basis. The taking of genetics into the field and city, that is, into real life, had begun, and a similarity of the field-work of Dr. Ford on butterflies and the sickle-cell anæmia by Allison referred to by Prof. Penrose indicated that the whole of human society could be a vast genetic experiment. But Prof. Darlington ended his talk by saying that in view of the failure of the universities and especially the social scientists to keep abreast of the advances in fundamental or genetic biology, Dr. E. D. Adrian's suggestion, in his presidential address, that mankind should be handed over for treatment to the social scientists made him "gasp".

The genes are, to use Darlington's phrase, the "long-range determiners". of not only morphological peculiarities but also of human behaviour: this is still not realized in universities and many research institutes. As for the public, it has always loathed the idea of genetic determination and has clung to the cherished and flattering old wives' tales that come within the framework of Lamarokism and not of genetics.

D. LEWIS

\section{WEATHER FORECASTING}

$T$ HE discussion on weather forecasting, arranged by Section A (Mathematics and Physics) of the British Association and held in Oxford on September 6 -as might be expected after a disastrous summer with weather more than usually a matter of public concern-drew a large gathering to the Sheldonian Theatre. The chair was taken by Prof. E. H. Neville and later by Sir Harold Spencer Jones, who introduced the guest speaker from Sweden, Prof. C. G. Rossby, now director of the Meteorological Institute of the University of Stockholm but equally renowned for his work in the United States, having held chairs in both Chicago and the Massachusetts Institute of Technology.

In opening the discussion with a paper on weather forecasting as a problem in physics, Dr. R. C. Sutcliffe first remarked that weather forecasting is something more than the science on which it rests; it is a scientific profession with some hundreds of practitioners issuing some thousands of forecasts 